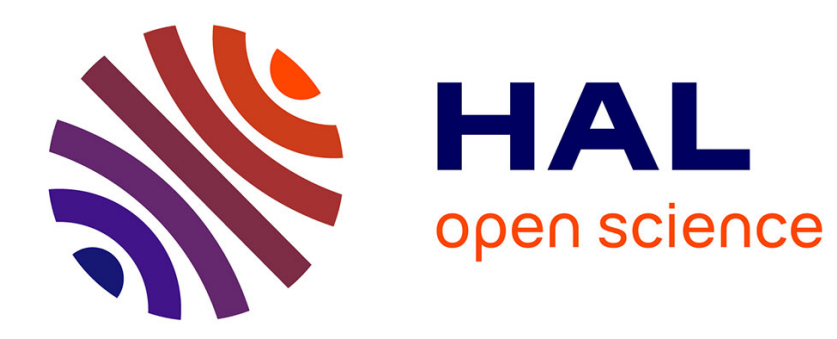

\title{
Risk aversion and technology mix in an electricity market
}

Guy Meunier

\section{- To cite this version:}

Guy Meunier. Risk aversion and technology mix in an electricity market. 2013. hal-00906944

\section{HAL Id: hal-00906944 \\ https://hal.science/hal-00906944}

Preprint submitted on 20 Nov 2013

HAL is a multi-disciplinary open access archive for the deposit and dissemination of scientific research documents, whether they are published or not. The documents may come from teaching and research institutions in France or abroad, or from public or private research centers.
L'archive ouverte pluridisciplinaire HAL, est destinée au dépôt et à la diffusion de documents scientifiques de niveau recherche, publiés ou non, émanant des établissements d'enseignement et de recherche français ou étrangers, des laboratoires publics ou privés. 


\section{ECOLE POLYTECHNIQUE}

CENTRE NATIONAL DE LA RECHERCHE SCIENTIFIQUE

RISK AVERSION AND TECHNOLOGY MIX IN AN ELECTRICITY MARKET

Guy MEUNIER

Cahier $n^{\circ} 2013-23$

\section{DEPARTEMENT D'ECONOMIE}

Route de Saclay

91128 PALAISEAU CEDEX

(33) 169333033

http://www.economie.polytechnique.edu/ mailto:chantal.poujouly@polytechnique.edu 


\title{
Risk aversion and technology mix in an electricity market
}

\author{
Guy Meunier ${ }^{1}$ \\ INRA-UR1303 ALISS, 65 bd de Brandebourg, 94205 Ivry sur Seine, FRANCE \\ Ecole Polytechnique, Route de Saclay, 91128 Palaiseau, France
}

\begin{abstract}
This article analyzes the effect of risk and risk-aversion on the long-term equilibrium technology mix in an electricity market. It develops a model where firms can invest in baseload plants with a fixed variable cost and peak plants with a random variable cost, and demand for electricity varies over time but is perfectly predictable. At equilibrium the electricity price is partly determined by the random variable cost and the returns from the two kinds of plants are negatively correlated. When the variable cost of the peak technology is high the return of peak plants is low but the return to baseload plants is high. Risk-averse firms reduce the capacity of the riskiest technology and develop the capacity of the other, compared to risk-neutral firms. In the particular case where a risk-neutral firm invests heavily in baseload technology and only sparely in peak capacity, a risk-averse firm would invest less in baseload, increase peak capacity, and increase total installed capacity. Keywords: Electricity market; Technology mix; Risk aversion.
\end{abstract}

\footnotetext{
${ }^{1}$ Phone: 0033+49596971, e-mail: guy.meunier@ivry.inra.fr
} 


\section{1. introduction}

The purpose of this article is to analyze the influence of firms' risk aversion on the technology mix in an electricity market if the variable cost of a technology is random. In the electricity industry, the fundamental explanation for the existence of a technology mix is the great variability of the demand for electricity over the course of a year and the limited potential to utilize intertemporal arbitrage to smooth these variations. To address the time-variable nature of electricity demand, firms invest in several types of technology; baseload technologies are more efficient for frequent production, whereas peak technologies are employed for more sporadic production. In addition to this well-known variability of the electricity demand curve, electricity producers face numerous uncertainties with respect to costs of production. In particular, the prices of fossil fuels and $\mathrm{CO}_{2}$ emissions are uncertain. These uncertainties are likely to influence the technology mix that is chosen to meet the variable demand, particularly if firms are risk-averse.

A canonical model of an electricity market is used to consider a situation in which the demand curve is variable and two different technologies are available to produce electricity: a baseload technology and a peak technology. The variable cost of the peak technology is random. It is assumed that electricity producers anticipate the variability of the demand curve; moreover, these producers are regarded as risk-averse. In the risk-neutral benchmark situation, these firms invest in the technology mix that minimizes the expected cost of servicing the electricity demand. We consider how risk aversion modifies the equilibrium technology mix and investigate how this modification is related to the cost structure and the variability of electricity demand. 
This study demonstrates that risk-aversion modifies the technology mix in either one of two directions: (i) the baseload capacity is increased, although the peak and total capacity are reduced; or (ii) the baseload capacity is reduced, but the peak and the total capacity are increased. In the latter situation, compared with the risk-neutral benchmark, risk-averse firms overinvest in both the risky technology and their total capacity.

The uncertainty with respect to the variable cost of the peak technology translates into an uncertainties in the electricity prices during the fraction of the year in which the peak technology establishes these prices. Both technologies have risky returns. The risk faced by peak units is related to the fraction of the year in which the peak technology is a sub-marginal source of electricity, whereas the risk faced by baseload units is related to the fraction of the year during which the peak technology establishes the price. Thus, the two technologies face negatively correlated risks. In certain circumstances, the baseload technology involves higher risk than the peak technology, and risk-averse firms will therefore tend to decrease their quantity of baseload capacities and increase their capacities of the risky peak technology to hedge against the risk incurred by baseload capacities.

The influence of the cost structure and the variability of electricity demand is also investigated. Among other conclusions, this study demonstrates that over-investment in the peak technology is more likely to arise when demand is less variable. This result is of particular interest if the framework of this study is applied to considerations of environmental policy because in these considerations, the peak technology may represent a polluting method of generating electricity. Thus, the development of renewable intermittent 
electricity production might induce an increase in peak capacity through increasing the variability of the (residual) load (Lamont, 2008). Our results reveal that this effect could be softened if firms are risk-averse and if the future price of $\mathrm{CO}_{2}$ emissions is uncertain. However, the environmental benefit from real-time-pricing (Holland and Mansur, 2011) might be reduced if producers are risk-averse.

The questions of whether firms are risk-averse and what the consequences of firms' potential risk aversion may be are issues that have received a considerable attention both in the general literature and in studies of energy and resource economics. With a complete sets of markets (Arrow and Debreu, 1954), firms' profits are not random and whether they are risk-averse or not does not matter. If markets are incomplete, Diamond (1967) suggests that firms should be risk-neutral, and shareholders should use capital-asset markets to hedge their risks. However, there are several theoretical arguments (for a review, see Banal-Estanol and Ottaviani, 2006) and certain empirical evidence that suggests that firms are risk-averse or at least behave as if they are risk-averse. ${ }^{2}$

Numerous authors have considered how risk aversion influence production choices in situations that feature random demand and perfect competition (Dhrymes, 1964; McCall, 1967; Baron, 1970; Sandmo, 1971; Appelbaum and Katz, 1986) or scenarios that involve monopolies (Baron, 1971; Leland, 1972) or oligopolies (Tessitore, 1994; Wambach, 1999; Asplund, 2002; Banal-

\footnotetext{
${ }^{2}$ For instance risk aversion can explain corporate hedging activity (Amihud and Lev, 1981; Nance et al., 1993; May, 1995), and Wolak and Kolstad (1991) have empirically investigated how risk aversion can explain Japanese firms' choices of coal suppliers.
} 
Estanol and Ottaviani, 2006). The assumption regarding the risk aversion of firms has also been used to analyze the firms' use of not only financial futures and option contracts (McKinnon, 1967; Newbery and Stiglitz, 1981; Moschini and Lapan, 1995) but also vertical integration (Hirshleifer, 1988; Aïd et al., 2011).

In a situation featuring random input prices, Stewart (1978) demonstrates that a risk-averse firm over-invests in riskless factors. Input price risks have also been analyzed by Blair (1974) and by Okuguchi (1977), but none of these analyses have addressed the issue of technological diversification. Recently, Meunier (2012) considers the effect of risk aversion on choices between two risky technologies; however, he does not consider the variability of the demand but instead regards risk-aversion as the sole explanation for technological diversification. Furthermore, he assumes the existence of an exogenous correlation that arises endogenously in the current study.

In the electricity industry, the influence of producers' risk-aversion on investment decisions is a central issue because electricity prices demonstrate a high variability and because of the uncertainty that surround the development of fossil fuel markets and environmental regulations. Neuhoff and De Vries (2004) provide a formal analysis of the influences of risk and of electricity producers' risk-aversions on the producers' investment choice with respect to a single technology. Willems and Morbee (2010), who build on the framework of Bessembinder and Lemmon (2002), consider the effect of financial options on both welfare and investment decisions. They do not consider the choice of technology mix but consider the incentive of a risk-averse producer to invest in one plant. They show that the initial development of 
financial markets can reduce the incentive to invest in peak plants. They do not consider the fact that investment in one type of plant can be used to hedge risks associated with other types of plants.

In the presence of several risky technologies, a financial portfolio framework (à la Markowitz, 1952) has been utilized by Bar-Lev and Katz (1976) to analyze the "technology portfolio". In particular, Bar-Lev and Katz (1976) evaluate the mix of fossil fuels of regulated electricity utilities. ${ }^{3}$ Roques et al. (2008) adopt a more positive perspective and determine the efficiency frontier (the expected return versus variance) of portfolios that are composed of combined cycle gas turbine (CCGT) plants, coal plants and nuclear plants for a price-taking firm that faces random electricity and gas prices. These researchers consider exogenous electricity prices and do not analyze the market equilibrium. In particular, they stress the role of the correlation between electricity and gas prices; however they had to assume this correlation, whereas this relationship arises endogenously in our framework.

Two recent works possess similarities to the present study. Ehrenmann and Smeers (2011) use numerical simulation of an electricity industry equilibrium to assess the influence of electricity producers' risk-aversion on the total capacity that is built and on the producers' technology mix. They consider several sources of uncertainty, including the design of the $\mathrm{EU} \mathrm{CO}_{2}$ permit trading scheme and the evolution of fossil fuel markets. Fan et al. (2010, 2011) also perform numerical simulations of the equilibrium of an electricity

\footnotetext{
${ }^{3}$ This framework has been used by several authors to evaluate national portfolios (Humphreys and McClain, 1998; Awerbuch, 2000; Awerbuch and Berger, 2003; Jansen et al., 2006).
} 
industry; they focus on the uncertainty surrounding $\mathrm{CO}_{2}$ prices and the effect of rules for allocating free allowances. They show that risk-aversion tends to favor investment in peak units (using gas) if permits are auctioned and not grandfathered. Compared with these two articles, we provide a tractable model; this model allows us to perform a formal analysis that contributes to a better understanding of the effects that risk produces on the technological mix and capacity of electricity producers.

The rest of the article is organized as follows: Section 2 introduces the model for this investigation. Subsequently, Section 3 describes the equilibrium in the risk-neutral benchmark situation and in the case of a risk-averse firm. Section 4 provides a generalized version of the model that incorporates more than two technologies. Section 5 considers the normative aspects of the model. Section 6 concludes.

\section{The model}

We consider a simple electricity system. The demand side is represented by a variable inelastic demand with a year's duration normalized to a value of 1 . Electricity demand $x$ is assumed to be distributed in $[0, X]$ with a cumulative distribution function $F(x)$. The function $F$ is positive, increasing and differentiable, and its derivative $F^{\prime}=f$ is the distribution of the load; in other words, $f(x)$ represents the duration of the year during which the demand for electricity is $x$. The "load duration curve" is the curve $F^{-1}(1-t){ }^{4}$

\footnotetext{
${ }^{4}$ The load duration curve is obtained by ranking hourly demands in decreasing order, so that for each date $t$ the corresponding quantity is such that the demand is larger than this quantity during $t$.
} 
The typical shape of a load duration curve is depicted in Figure 1(b).

The real time demand for electricity is $x$ if the price is below $v$ and 0 otherwise, $v$ is the "value of the lost load" (VoLL). The instantaneous surplus when the demand is $x$ and a quantity $y<x$ (resp. $y>x$ ) of electricity is served is $v y$ (resp. $v x$ ) in $\$$ per time. The total surplus is the sum over the year of the flow of instantaneous surplus.

There are two technologies to produce electricity; these are labeled $t=b$ and $t=p$ to represent the baseload and peak technologies. As a concrete illustration we have in mind nuclear for the baseload technology and CCGT for peak units. Each technology $t$ is characterized by a variable cost $c_{t}(\$$ per $\mathrm{W}$ yr) and a capacity cost $I_{t}(\$$ per $\mathrm{W})$. The variable cost of the peak technology is assumed to be random at the time of investment. We assume that the variations of $c_{p}$ are sufficiently small to ensure that $v>c_{p}>c_{b}$ for all realizations. Finally, the expected value of $c_{p}$ is $\bar{c}_{p}$ and its standard deviation $\sigma$.

The baseload technology $b$ provides less costly production per unit of electricity throughout the year than the peak technology $p$, but the baseload technology is more costly than the peak technology for production over a short period:

$$
\begin{gathered}
c_{b}+I_{b}<\bar{c}_{p}+I_{p}, \quad \text { and } I_{p}<I_{b} \\
\$ / \mathrm{W} \cdot \mathrm{yr} \times 1 \mathrm{yr}+\$ / W
\end{gathered}
$$

The ratio $r=\left(I_{b}-I_{p}\right) /\left(\bar{c}_{p}-c_{b}\right)$ is the portion of a year such that technology $b$ is more efficient than $p$ for production over a longer period than $r$. The ratios $r_{p}=I_{p} /\left(v-\bar{c}_{p}\right)$ and $r_{b}=I_{b} /\left(v-c_{b}\right)$ are the minimal duration of production with the peak and baseload technologies, respectively, such that 
the aggregate expected cost from each technology is lower than the consumer surplus. The duration $r_{p}$ is assumed to be less than one, i.e. $v>\bar{c}_{p}+I_{p}$, and lower than $r, r_{p}<r$; this last assumption ensures that technology $p$ is used at equilibrium; it is equivalent to the statements that $r_{p}<r_{b}$ and $r_{b}<r$. These features are illustrated in figure 1(a).

It is assumed that there is a set $I$ of $n$ firms. Individual capacities of firm $i \in I$ for each technology are denoted by $k_{b}^{i}$ and $k_{p}^{i}$ and its aggregate capacity is $k^{i}=k_{b}^{i}+k_{p}^{i}$. Thus, the aggregate quantities of the capacities of all firms for each technology are: $k_{t}=\sum_{i} k_{t}^{i}$ for $t=b, p$ and $k=k_{b}+k_{p}$.

Once capacities are fixed, in the short term, the price is set at the marginal cost of the last unit that is utilized when all demand is satisfied, and at $v$ in case of "rationing", i.e., when $x>k$. If demand is less than $k_{b}$, the wholesale price is $c_{b}$, and baseload capacities produce. When demand is greater than $k_{b}$ and smaller than $k$ the price is $c_{p}$, baseload capacities are fully utilized and the quantity $x-k_{b}$ that remains is produced by peak capacities. For higher levels of the demand the price is $v$; because only $k$ units of electricity are consumed, a portion $x-k$ of the demand is not satisfied.

The profit of a firm $i \in I$ may be expressed as follows:

$$
\begin{aligned}
\pi^{i}= & \int_{k_{b}}^{k}\left(c_{p}-c_{b}\right) k_{b}^{i} f(x) d x+\int_{k}^{X}\left[\left(v-c_{p}\right) k_{p}^{i}+\left(v-c_{b}\right) k_{b}^{i}\right] f(x) d x \\
& -I_{b} k_{b}^{i}-I_{p} k_{p}^{i} .
\end{aligned}
$$

The portion of the year during which rationing occurs is $T=1-F(k)$ and the portion of the year during which the baseload capacity is fully utilized is $T_{b}=1-F\left(k_{b}\right)$. With these notations, the profit of a firm may be rewritten 
as a function of its aggregate capacity and baseload capacity:

$$
\pi^{i}\left(k_{b}^{i}, k^{i}, c_{p}\right)=\left[T\left(v-c_{p}\right)-I_{p}\right] k^{i}+\left[T_{b}\left(c_{p}-c_{b}\right)-\left(I_{b}-I_{p}\right)\right] k_{b}^{i} .
$$

For $i \in I$, the risk-aversion of firm $i$ is denoted by $\lambda^{i}$, a positive real number. The objective function of firm $i$ is

$$
U^{i}=\mathbb{E}\left[\pi^{i}\right]-\frac{\lambda^{i}}{2} \operatorname{var}\left(\pi_{i}\right) .
$$

Firms are assumed to be price takers, they consider the distribution of electricity prices to be given and they choose their capacity in a manner that maximizes their objective. The risk-aversion of firms is related to the uncertainty of the variable cost $c_{p}$ but not to the variability in the demand for electricity which is perfectly anticipated.

The essential feature of the framework is that the variable cost $c_{p}$ determines the price of electricity during a fraction of the year. Consequently, with endogenous electricity prices, the revenues from peak plants and baseload plants are negatively correlated: when $c_{p}$ is large, the former is low and the latter is large. Risk-averse firms adjust their technology mix in order to reduce the variation of their profit. The influence of the variable cost $c_{p}$ on the profit of a firm determines in which type of plant the firm invest to smooth its profit's variation.

The effect on a firm's profit of an increase of the variable cost $c_{p}$ depends on the quantities of each type of plants and on the number of hours the peak technology is marginal and inframarginal. The overall effect of an increase of $c_{p}$ is $d \pi / d c_{p}=-T k^{i}+T_{b} k_{b}^{i}$, which is either positive or negative; depending on this sign, a risk-averse firm will tend to distort its mix toward the peak or the baseload technology to hedge its risk. 


\section{Risk aversion and equilibrium.}

Before we examine the effect of risk aversion, we consider the risk-neutral benchmark situation.

\subsection{The risk-neutral case}

If a firm is risk-neutral, i.e. $\lambda^{i}=0$, then the equilibrium technology mix will generate a null expected profit for the firm (because of the linearity of the framework). From equation (2), it implies the following relationships for the risk-neutral duration $T^{*}$ and $T_{b}^{*}$ :

$$
\begin{array}{r}
\left(v-\bar{c}_{p}\right) T^{*}=I_{p} \Leftrightarrow T^{*}=r_{p} ; \\
\left(\bar{c}_{p}-c_{b}\right) T_{b}^{*}=I_{b}-I_{p} \Leftrightarrow T_{b}^{*}=r .
\end{array}
$$

The first of these two relationships states the typical association that relates the value of lost load $v$ and the loss of load probability $T$ to the variable and capacity costs of the peak technology. The second of these equations indicates the technology mix that minimizes the expected production cost. From these equations, an expression for the risk-free technology mix is:

$$
k^{*}=F^{-1}\left(1-r_{p}\right), k_{b}^{*}=F^{-1}(1-r)
$$

In Figure 1, the risk-neutral benchmark scenario is depicted. The optimal mix is obtained from the load duration curve, $F^{-1}(1-t)$, and the durations $r$ and $r_{p}$.

The quantities $k^{*}$ and $k_{b}^{*}$ correspond to the technology mix chosen in the absence of risk aversion or in the absence of risk; in these cases, they correspond to the welfare-maximizing investment. In Section 4, we further elaborate on the normative properties of this technology mix. 

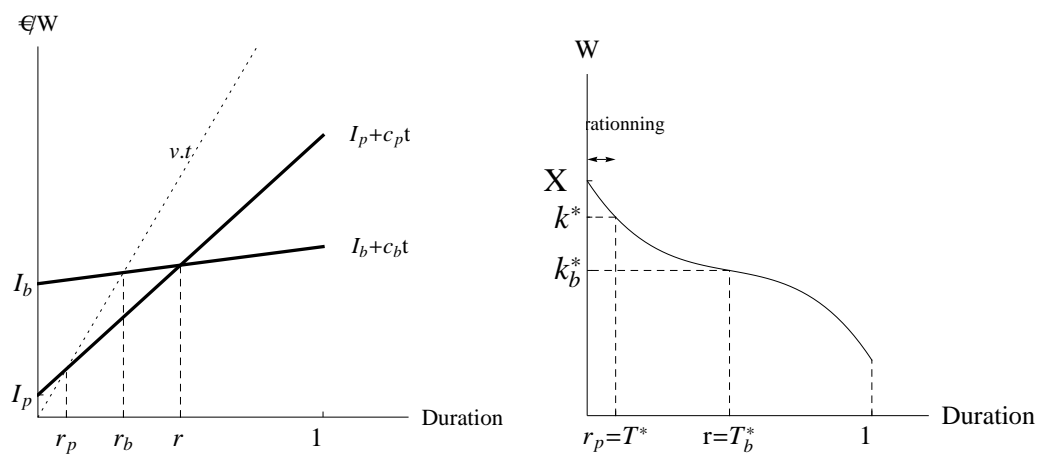

(a) Cost and production durations (b) Load curve and equilibrium investment

Figure 1: Cost structure, load curve $\left(F^{-1}(1-t)\right)$ and equilibrium investment in the riskneutral case

\subsection{Risk aversion}

Consider the situation in which all firms are risk-averse. Each firm $i \in I$ maximizes its objective function, expressed by equation (3). Given our choice of variables, the firm will choose its total capacity as if the entire capacity was based on the peak technology, and the firm will determine the share of baseload capacity by considering the effects of substituting a peak unit for a baseload unit. At an interior solution, the marginal increase in expected profit is equalized with the marginal increase in weighted variance for each technology.

Lemma 1. At equilibrium, both technologies are used and the following equations are satisfied

$$
\begin{array}{r}
\left(v-\bar{c}_{p}\right) T-I_{p}=\Lambda \sigma^{2} T\left(T k-T_{b} k_{b}\right) \\
\left(\bar{c}_{p}-c_{b}\right) T_{b}-\left(I_{b}-I_{p}\right)=\Lambda \sigma^{2} T_{b}\left(T_{b} k_{b}-T k\right)
\end{array}
$$


in which

$$
\Lambda=\left[\sum_{i \in I} \frac{1}{\lambda_{i}}\right]^{-1}
$$

This lemma allows for a representative firm with risk aversion $\Lambda$ and capacities $k$ and $k_{b}$ to be considered through the analysis of equations (7) and $(8) .5$

Compared to the risk-neutral benchmark, described by (4) and (5), a risk-averse firm has an incentive to soften the variations of its profit. This incentive is reflected in the right-hand sides of equations (7) and (8) which are null in the risk-neutral case. When $c_{p}$ is large the return from peak plants is low and the return from baseload plants is large. The short-term revenue is either increasing or decreasing with respect to $c_{p}$. Depending on this monotonicity investing in a peak plant will tend to either increase or reduce the variability of the firm's profit. Overall, the effect on the variance of a firm's profit of adding a peak plant or substituting a peak plant to a baseload plant have opposite sign. The former is $T\left(T k^{i}-T_{b}^{i} k_{b}^{i}\right)$ and the latter $T_{b}\left(T_{b} k_{b}^{i}-T^{i} k^{i}\right)$. This feature implies that the comparison with the risk-neutral benchmark is clear-cut.

Proposition 1. There is at least one equilibrium in the case of risk aversion. Each equilibrium with risk aversion is of one of the following two types:

Type B: the total capacity is lower than $k^{*}$, the baseload capacity is larger than $k_{b}^{*}$, and the peak capacity is lower than $k_{p}^{*}$.

\footnotetext{
${ }^{5}$ At equilibrium, each firm has a degree of freedom with respect to its choices. Each firm is indifferent with respect to its total capacity but not to its technological mix.
} 
Type P: the total capacity is larger than $k^{*}$, the baseload capacity is lower than $k_{b}^{*}$, and the peak capacity is larger than $k_{p}^{*}$.

The proof is presented in Appendix B. ${ }^{6}$ There are only two possible distortions of the technology mix; the effect on the total capacity is similar to the effect on the quantity of peak plants because those plants are the marginal ones. It is possible to specify conditions for the parameters of a particular scenario that ensures that a Type B or a Type P equilibrium will exist.

Proposition 2. If $T^{*} k^{*}>T_{b}^{*} k_{b}^{*}$, then there is one equilibrium of Type B; if $T^{*} k^{*}<T_{b}^{*} k_{b}^{*}$, then there is one equilibrium of Type $P$.

The proof is presented in Appendix C. The difference $T^{*} k^{*}-T_{b}^{*} k_{b}^{*}$ corresponds to the risk exposure of the firm in the risk-neutral benchmark. It could be rewritten as the difference:

$$
T^{*} k^{*}-T_{b}^{*} k_{b}^{*}=T^{*}\left(k^{*}-k_{b}^{*}\right)-\left(T_{b}^{*}-T^{*}\right) k_{b}^{*}
$$

The quantity $T^{*}\left(k^{*}-k_{b}^{*}\right)$ is the quantity of electricity that is sold at price $v$ and costs $c_{p}$, and $\left(T_{b}^{*}-T^{*}\right) k_{b}^{*}$ is the quantity of electricity from baseload capacity that is sold at price $c_{p}$. The difference between the two determines whether the profit of a firm with the risk-neutral portfolio is positively correlated to the marginal cost $c_{p}$. And this sign, in turn, determines in which direction the firm should modify its mix to smooth the variations of its profit.

\footnotetext{
${ }^{6}$ Because of market incompleteness there might be several equilibria, and some restrictions on the load duration curve would ensure uniqueness of the equilibrium.
} 
If $T^{*} k^{*}-T_{b}^{*} k_{b}^{*}$ is positive (resp. negative), the profit of the firm is increasing (resp. decreasing) with respect to $c_{p}$ and developing its baseload capacity (resp. peak capacity) smooths its profit variations.

In Figure 2, an equilibrium of Type $\mathrm{P}$ is depicted. The difference $T^{*} k^{*}-$ $T_{b}^{*} k_{b}^{*}$ is the difference between the two areas below the load duration curve, it is negative for the case depicted. From equations (7) and (8), the risk-averse equilibrium is similar to a risk-neutral equilibrium with an adjusted peak variable cost. The equilibrium "risk premium" added to the variable cost is equal to the difference $\Lambda \sigma^{2}\left(T k-T_{b} k_{b}\right) .{ }^{7}$ The effect of risk aversion could be visualized by rotating the peak line $I_{p}+c_{p} t$; on Figure 2(a), the rotation is clockwise. The corresponding shift of capacity is indicated in Figure 2(b).

In Figure 2, relative to the risk-neutral situation, risk-averse firms will tend to display lower shares of the baseload technology but greater total capacity. In this situation, the expected return from peak capacity is negative, whereas both the return from baseload capacity and the overall expected profit are strictly positive.

\footnotetext{
${ }^{7}$ This risk premium is not common to all firms, firm $i$ premium is $\lambda^{i} \sigma^{2}\left(T k^{i}-T_{b} k_{b}^{i}\right)$.
} 


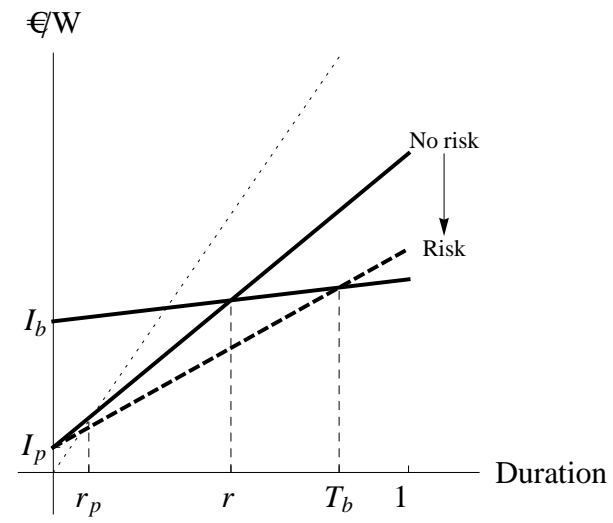

(a) The effect of risk is similar to a clockwise rotation of the peak plant cost.

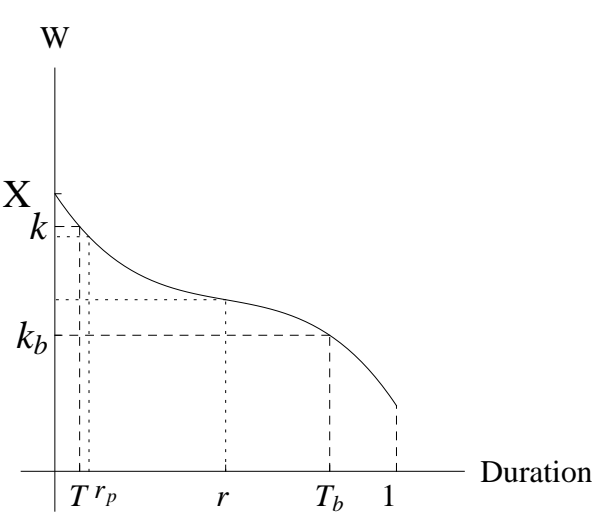

(b) The risk-averse equilibrium (dashed lines) compared to the risk-neutral benchmark (dotted lines).

Figure 2: A Type $\mathrm{P}$ equilibrium. This equilibrium involves a larger total capacity and a lower baseload capacity than the equilibrium in the risk-neutral benchmark scenario.

\subsection{The influence of the cost structure}

The answer to whether an equilibrium with risk-averse firms will be of Type B or Type $\mathrm{P}$ relates to the cost structure and the shape of the load duration curve. We begin this facet of the analysis with a discussion of the influence of the cost structure and subsequently consider the influence of the load duration curve. The Voll and the four cost parameters determine the two durations $r$ and $r_{p}$ that will be used to conduct the discussion.

From Proposition 2, the existence of an equilibrium of Type $\mathrm{B}$ or Type $\mathrm{P}$ is related to the sign of the difference $T^{*} k^{*}-T_{b}^{*} k_{b}^{*}$. The risk that is associated with a technology is the product of two factors: the duration of the full use of this technology, which is either $r$ or $r_{p}$, and the corresponding capacity. The latter is decreasing with respect to the former so that the product of the two is not monotonic. For any $r$ there is a value of the parameter $r_{p}$ such that 
the difference $T^{*} k^{*}-T_{b}^{*} k_{b}^{*}$ is strictly negative; moreover, if $r$ is sufficiently large there is another value such that the aforementioned difference is strictly positive. By constraining the shape of the distribution $F$, it is possible to obtain a stronger result.

Corollary 1. If $t F^{-1}(1-t)$ is strictly concave, then for any $r$ there is a threshold $\tilde{r}_{p}$ such that there is a Type $B$ (resp. Type P) equilibrium if $r_{p}<\tilde{r_{p}}$ $\left(\right.$ resp. $\left.r_{p}>\tilde{r_{p}}\right)$.

Proof. If $t F^{-1}(1-t)$ is strictly concave, there is a unique $t_{\max } \in(0,1)$ that maximizes $t F^{-1}(1-t)$ (because this function is null at 0 and 1 ). For $r \leq t_{\max }, r_{p} F^{-1}\left(1-r_{p}\right)<r F^{-1}(1-r)$ for all $r_{p} \in[0, r)$, and $\tilde{r}_{p}=r$. For $r>t_{\max }$ there is $\tilde{r}_{p}<r$ such that $\tilde{r}_{p} F^{-1}\left(1-\tilde{r}_{p}\right)=r F^{-1}(1-r)$ and $r_{p} F^{-1}\left(1-r_{p}\right)<r F^{-1}(1-r) \Leftrightarrow r_{p}<\tilde{r}_{p}$.

In Corollary 1, the duration $r$ is maintained at a fixed level, and variations of the duration $r_{p}$ are considered. Figure 3(b) graphically illustrates this corollary. Three extreme situations are worth considering: the two technologies could be very different (large $r$ and small $r_{p}$ ) or relatively similar with both technologies being used for baseload supply (large $r$ and $r_{p}$ ) or to meet peak demand (small $r$ and $r_{p}$ ).

If the two technologies are very different ( $r$ is large and $r_{p}$ is small), there is a large investment in the peak technology, and the variable cost of this technology establishes the price of electricity for a large portion of the year; however firms are not frequently at full capacity $\left(r_{p}\right.$ is small). Consequently, the risk that is faced by technology $p$ is small, while the risk that is faced by 
the baseload technology is large. As a result, relative to the benchmark case of risk-neutrality, the overall investment of these firms will be increased, and the technological mix will be adjusted towards the peak technology.

If both technologies are similar and peak-oriented, $p$ is effectively a peak technology and $b$ could be described as a midload one. There is a large investment in this technology and a small investment in the peak technology. The technology $b$ faces a large risk and risk-averse firms increase their investment in the peak technology to hedge this risk. Compared to the previous case, the large risk associated with technology $b$ has a different explanation. In the previous case, this risk was due to a large duration of full use with a price at $c_{p}$; by contrast, in the current case it comes from the large investment in this technology.

If both technologies have similar cost structure and both $r$ and $r_{p}$ are close to 1 , technology $p$ is a midload technology and the two technological options are substitutable for production throughout the course of the year. In this situation, there is a small investment in technology $p$, it is frequently fully utilized and is rarely infra-marginal. In this scenario, technology $p$ is highly risky and risk-averse firms will therefore attempt to reduce their risks by decreasing their quantities of this technology and increasing their quantities of the baseload technology.

\subsection{The influence of the variability of the load}

It has been shown that risk-aversion tends to modify the technology mix in either one of two directions. This is related to the variability of the load. A linear load duration curve is used on Figure 3(a) to consider the influence 
of the variability of the load on the equilibrium type. ${ }^{8}$
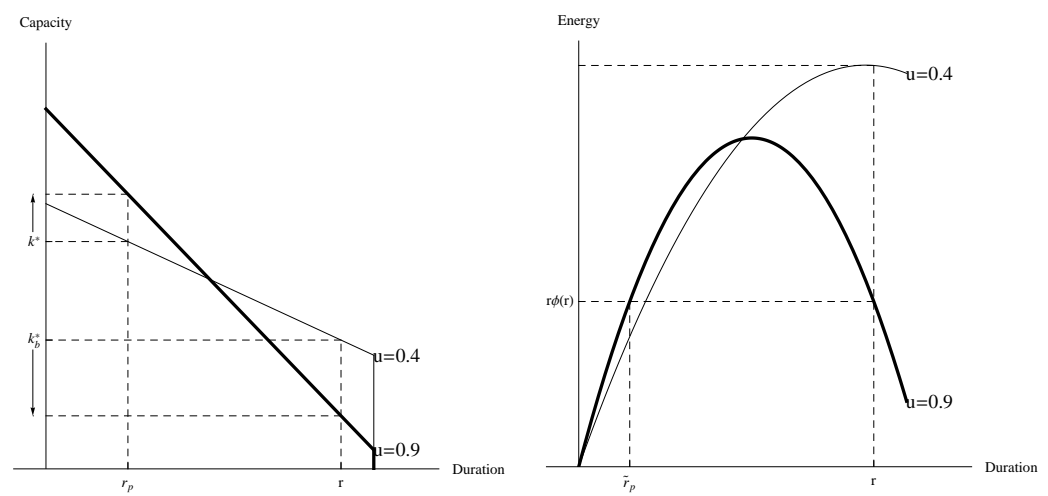

(a) Two load duration curves and (b) The marginal risk from investthe corresponding technological ment $T . k$ with the two load duramixes tion curves, and the threshold $\tilde{r}_{p}$ of Corollary 1

Figure 3: The effect of the load duration curve on the marginal risk from investment, with a linear load duration curve $\bar{X}[(1+u) / 2-u . t]$.

In Figure 3(b), two load duration curves with different variability are depicted. With a more variable load, the quantity of total capacity increases, and the quantity of baseload capacity decreases. With a highly variable load, as represented by the thick line in Figure 3, the riskiest component of firms' profits are obtained from their total capacities rather than from their baseload capacities; in these cases, a Type B equilibrium exists, and firms will tend to increase their baseload capacities and reduce their total capacities.

\footnotetext{
${ }^{8}$ The demand $x$ is homogeneously distributed over $[\bar{X}(1-u) / 2, \bar{X}(1+u) / 2]$, the corresponding load duration curve is $\bar{X}[(1+u) / 2-u . t]$. The quantity $\bar{X}$ represents the total quantity of electricity that is demanded over the course of one year, and $u$ represents the variability of the load.
} 
With a relatively stable load, as represented by the thin line in Figure 3, firms will possess small quantities of peak capacity and a Type P equilibrium will exist. In these situations, the return from peak units will be negatively correlated with the overall profit of the firm, and the firm will tend to increase its investment in peak units to hedge the risk from the baseload production, which constitutes its main source of profit.

\section{Welfare}

In the above analysis, we determined how risk and risk aversion modify the technology mix. The benchmark used was the risk-neutral situation that also described the absence of risk. However, it is also interesting to compare the long-run equilibrium with a welfare maximizing mix that would account for risk-aversion.

\subsection{Welfare function and $1^{\text {st }}$ best technology mix}

For a realization $c_{p}$ of the variable cost of the peak technology, the consumer surplus is the sum of the difference between the gross surplus and the price:

$$
C S\left(k, k_{b}, c_{p}\right)=\int_{0}^{k_{b}}\left(v-c_{b}\right) x f(x) d x+\int_{k_{b}}^{k}\left(v-c_{p}\right) x f(x) d x
$$

If consumers are risk-neutral, their expected surplus is $C S\left(k, k_{b}, \bar{c}_{p}\right)$. Welfare is defined as the sum of the expected consumer surplus and the firms' utility:

$$
W\left(\mathbf{k}, \mathbf{k}_{b}\right)=C S\left(k, k_{b}, \bar{c}_{p}\right)+\sum_{i} U\left(\lambda^{i}, k_{b}^{i}, k^{i}\right)
$$

With this welfare function, it is implicitly assumed that transfers between consumers and firms are feasible ex-ante, when $c_{p}$ is unknown, and not expost, when $c_{p}$ is known. 
If transfers could be implemented ex-post and made conditional on the realization of the marginal cost $c_{p}$, a social planner would ensure that firms earns a constant profit to cancel out the cost due to risk-aversion. ${ }^{9}$ In such a case, the first-best optimal investment would be equal to the risk-neutral equilibrium investment, and it could be decentralized via a complete set of markets. Such a complete set of markets would associate a price for electricity for each realization of $c_{p}$ and each hour of the year (i.e., each demand level $x$ in our framework).

\subsection{Constrained optimum}

From the equation (11), the second best optimal investment schedule would satisfy:

$$
\begin{array}{r}
(v-\bar{c}) T-I_{p}=\lambda^{i} \sigma^{2} T\left(T k^{i}-T_{b} k_{b}^{i}\right)+\sum_{j \in I} \lambda^{j} \sigma^{2}\left(T k^{j}-T_{b} k_{b}^{j}\right) T^{\prime} k^{j} \\
\left(\bar{c}-c_{b}\right) T_{b}-\left(I_{b}-I_{p}\right)=\lambda^{i} \sigma^{2} T_{b}\left(T_{b} k_{b}^{i}-T k^{i}\right)+\sum_{j \in I} \lambda^{j} \sigma^{2}\left(T_{b} k_{b}^{j}-T k^{j}\right) T_{b}^{\prime} k_{b}^{j}
\end{array}
$$

Compared with the risk-neutral (and first best) investment, there are additional terms related to risk aversion. The investment of a firm does not only directly affect its own risk but also indirectly affects the risk of all firms (including itself) via the change of the durations $T$ and $T_{b}$.

\footnotetext{
${ }^{9}$ If a transfers scheme $t^{i}\left(c_{p}\right)$ could be implemented, then, for a variable cost $c_{p}$, the profit of firm $i$ would be $\pi^{i}+t^{i}\left(c_{p}\right)$ and consumers surplus $C S-\sum_{i} t^{i}\left(c_{p}\right)$. The regulator could set $t^{i}\left(c_{p}\right)=\bar{\pi}^{i}-\pi^{i}$ to stabilize the firm revenue and strictly increase the welfare.
} 
Because of market incompleteness, there is an externality associated with each firm investment. The sign of the externality associated with the peak capacity of a firm is opposite to the sign of the externality associated with the baseload capacity of this firm. At the market equilibrium, these signs are related to the equilibrium type. For instance, if the equilibrium is of Type $\mathrm{B}$, an increase of the total capacity of a firm and a decrease of its baseload capacity would reduce the risk faced by all firms. The reverse holds for an equilibrium of Type P.

In order to compare the equilibrium portfolio with the second best, a representative firm could be considered so that the second best technology mix satisfies the two equations:

$$
\begin{array}{r}
(v-\bar{c}) T-I_{p}=\Lambda \sigma^{2}\left(T k-T_{b} k_{b}\right)\left(T+T^{\prime} k\right) \\
\left(\bar{c}-c_{b}\right) T_{b}-\left(I_{b}-I_{p}\right)=\Lambda \sigma^{2}\left(T_{b} k_{b}-T k\right)\left(T_{b}+T_{b}^{\prime} k_{b}\right) .
\end{array}
$$

The comparison between the market equilibrium and the second best is not straightforward because of the substitutability between the two types of capacity. Even though at an equilibrium of Type B an increase of $k$ or a decrease of $k_{b}$ would increase welfare, ${ }^{10}$ it is not possible to conclude that there is an under-investment in total capacity and an over-investment in baseload capacity. This is so because an increase of the total capacity can increase the marginal benefit from a baseload capacity via its effect on the risk-exposure of firms. In such a case there might be an under-investment in both types of technology.

\footnotetext{
${ }^{10} \mathrm{At}$ an equilibrium of Type B, the derivative of welfare w.r.t. $k$ (resp. $\left.k_{b}\right)$ is $-(T k-$ $\left.T_{b} k_{b}\right) T^{\prime} k$ (resp. $\left.\left(T k-T_{b} k_{b}\right) T_{b}^{\prime} k_{b}\right)$ which is positive (resp.negative).
} 
Formally this issue is related to the sign of the cross derivative of welfare with respect to $k$ and $k_{b}$, which is $\partial^{2} W / \partial k_{b} \partial k=\Lambda \sigma^{2}\left(T+T^{\prime} k\right)\left(T+T^{\prime} k_{b}\right)$. The sign of this expression varies with capacities; if both quantities are close (so that $k_{b}$ is a large share of $k$ ) it is positive which would ensure that the comparison is intuitive. However, if the two quantities are sufficiently different it could be negative and the comparison cumbersome. This issue would require further work. However, if the risk-aversion of firms or the risk are sufficiently small, the cross effect would be dominated by the direct effect and the comparison between the market equilibrium and the second best mix would be similar than the comparison between the market equilibrium and the first best mix. ${ }^{11}$

\section{A generalization to a situation with more than two technologies}

In this section, a broader version of the model is developed to understand the generalizability of results that have previously been described.

In this broader version of the model, there are $m$ technologies labeled $j=1 . . m$, which are ordered in terms of increasing variable cost $c_{j}$ and decreasing capacity cost $I_{j}$ :

$$
0<c_{1}<c_{2}<\ldots<c_{m}<v \text { and } 0<I_{m}<I_{m-1}<\ldots<I_{1}
$$

The variable costs are assumed to be independently distributed random variables with mean $\bar{c}_{j}$ and standard variation $\sigma_{j}$. The risks are assumed to be

\footnotetext{
${ }^{11}$ Note that the comparison between the first best (i.e. risk-neutral) mix and the 2 nd best mix is ambiguous because the signs of $T+T^{\prime} k$ and $T_{b}+T_{b}^{\prime} k_{b}$ vary with $k$ and $k_{b}$.
} 
sufficiently small such that the merit order is never modified. In accordance with the two-technology framework, the duration $r_{j}$ is defined as:

$$
r_{m}=\frac{I_{m}}{v-\bar{c}_{m}} \text { and } r_{j}=\frac{I_{j}-I_{j+1}}{\bar{c}_{j+1}-\bar{c}_{j}} \text { for } j \leq m-1
$$

Moreover, we assume that $0<r_{m}<r_{m-1}<\ldots<r_{1}<1$ to ensure that all technologies are used.

We consider a representative firm with risk aversion $\Lambda$. This firm's capacity of technology $j$ is $k_{j}$, and we use $K_{j}$ to denote the sum of the capacities of technologies lower than $j$, that is

$$
K_{j}=\sum_{l=1}^{j} k_{l}, \text { and } K_{0}=0
$$

The price of electricity is the variable cost $c_{j}$ if $K_{j-1} \leq x<K_{j}$ and the price is $v$ in case of rationing. Therefore, the price of electricity is $c_{j}$ during a portion $F\left(K_{j}\right)-F\left(K_{j-1}\right)$ of the year and $v$ during the remaining $1-F\left(K_{n}\right)$ of the year. We use $T_{j}$ to denote the portion of the year during which the price is strictly above $c_{j}: T_{j}=1-F\left(K_{j}\right)$. The profit of the representative firm may then be expressed as follows:

$$
\Pi(\mathbf{k}, \mathbf{c})=\left[T_{n}\left(v-c_{n}\right)-I_{n}\right] K_{n}+\sum_{j=1}^{m-1}\left[T_{j}\left(c_{j+1}-c_{j}\right)-\left(I_{j}-I_{j+1}\right)\right] K_{j} .
$$

In the risk-neutral benchmark situation, the values of $T_{j}$ are equal to the ratios $r_{j}$ for $j=1 . . m$. The risk-averse firm has an objective function that is similar to (3). The variance of this firm's profit may be expressed as follows:

$$
\operatorname{var}(\Pi)=\sum_{j=2}^{m} \sigma_{j}^{2}\left(T_{j} K_{j}-T_{j-1} K_{j-1}\right)^{2}+\sigma_{1}^{2} T_{1} K_{1}^{2} .
$$


At equilibrium, the following first-order conditions are satisfied:

$$
\begin{aligned}
T_{m}\left(v-\bar{c}_{m}\right)-I_{m}= & \Lambda T_{m} \sigma_{m}^{2}\left(T_{m} K_{m}-T_{m-1} K_{m-1}\right) \\
T_{j}\left(\bar{c}_{j+1}-\bar{c}_{j}\right)-\left(I_{j}-I_{j+1}\right)=\Lambda T_{j}[ & \sigma_{j+1}^{2}\left(T_{j} K_{j}-T_{j+1} K_{j+1}\right) \\
& \left.+\sigma_{j}^{2}\left(T_{j} K_{j}-T_{j-1} K_{j-1}\right)\right] \\
T_{1}\left(\bar{c}_{2}-\bar{c}_{1}\right)-\left(I_{1}-I_{2}\right)=\Lambda T_{1}[ & \left.\sigma_{2}^{2}\left(T_{1} K_{1}-T_{2} K_{2}\right)+\sigma_{1}^{2} T_{1} K_{1}\right] .
\end{aligned}
$$

\subsection{If only one technology is risky}

If $l>1$ is the sole risky technology, then the right-hand sides of the above first-order conditions are null for all $j$ except for $l$ and $l-1$, and for these two technologies the first-order conditions are:

$$
\begin{aligned}
T_{l}\left(c_{l+1}-\bar{c}_{l}\right)-\left(I_{l}-I_{l+1}\right) & =\Lambda T_{l} \sigma_{l}^{2}\left(T_{l} K_{l}-T_{l-1} K_{l-1}\right) \\
T_{l-1}\left(\bar{c}_{l}-c_{l-1}\right)-\left(I_{l-1}-I_{l}\right) & =\Lambda T_{l-1} \sigma_{l}^{2}\left(T_{l-1} K_{l-1}-T_{l} K_{l}\right)
\end{aligned}
$$

These two equations are similar to the first-order conditions (7) and (8) in the two technology framework with the VoLL $v$ replaced by the variable cost of technology $l+1$. Thus, the two aggregate capacities $K_{l}$ and $K_{l-1}$ are the only capacities modified by the introduction of risk aversion. The two technology case can then be applied to understand how the mix is distorted.

If we further assume that the two technologies $l$ and $l-1$ are sufficiently similar to ensure that $r_{l}$ and $r_{l-1}$ are close to each other, then we can deduce from the previous analysis that there will be an over-investment in the risky technology if it is a peak technology and that there will otherwise be an under-investment in this technology. 


\subsection{If several technologies are risky}

If several technologies are risky, the effect of risk aversion is more difficult to assess. Indeed, if the risky technologies are "isolated", that is, if technology $l$ is risky but technologies $l-1$ and $l+1$ are not risky, then there will be local distortions of the technology mix that could be analyzed in isolation.

If all the available technologies except for the baseload technology are risky, then the sum of the right-hand sides of equations (18), (19) and (20) will be null; thus, except for a single specific case, the introduction of risk aversion into the situation causes at least one of the $K_{j}$ to increase and at least one $K_{j}$ to decrease.

Furthermore, if the technologies, i.e. the $r_{j}$, are sufficiently close to each other, then it is possible to develop a notion of the effect of risk aversion on the two extreme technologies. In this situation, it is likely that the righthand side of equation (18) will be negative and that the right hand side of equation (20) will be positive; this result would imply that the introduction of risk aversion into the scenario would produce an increase in the total capacity and a reduction in the baseload capacity.

\section{Conclusion}

In an electricity market, the technology mix is fundamentally driven by the variability of the load. In this article, we have investigated the effect of

the risk aversion of firms on these firms' technology mixes when the cost of a technology is random.

In the model that was developed for this investigation, two technologies, a baseload technology and a peak technology, were assumed to be available 
to satisfy a variable demand for electricity. The variable cost of the peak technology was assumed to be random. In the presence of risk aversion, the total capacity may be either smaller or larger than the total capacity in the risk-neutral benchmark case. In the latter situation, the quantity of baseload capacity is lower and the quantity of peak capacity is larger with risk aversion than without. In this case firms tend to over-invest in the risky peak technology to hedge the risks associated with the baseload technology. These risks originate from the peak variable costs because those costs determine the electricity prices and the baseload short-term revenue.

This work clarifieq the effects of risk aversion on firms' investment decisions and hels to elucidate the mechanisms underlying these decisions. This study contributes to a greater understanding of how uncertainties surrounding fossil fuel prices impact the investment decisions of electricity producers. For instance the uncertainty surrounding gas prices has consequences for gas plants but also for other technologies with lower variable costs (e.g. nuclear, coal, renewable). Because the variable cost of a technology determines the short-term rent of technologies with lower variable costs, uncertainty only propagates down the merit order.

Moreover, this investigation might also be applicable to an analysis of the ways in which electricity producers may be affected by certain environmental regulations, such as the uncertainty surrounding the future regulation of greenhouse gas emissions. For instance, if the baseload technology is a $\mathrm{CO}_{2}$ free process, the analysis of this study could demonstrate how the uncertainty surrounding the $\mathrm{CO}_{2}$ price could lead to a reduction of investment in the clean baseload technology because of the risks that are associated with the $\mathrm{CO}_{2}$ - 
emitting technology. This putative environmentally detrimental distortion would be most likely to occur in situations that involve the least variable loads.

Aïd, R., Chemla, G., Porchet, A. and Touzi, N. (2011). Hedging and vertical integration in electricity markets, Management Science 57(8): 1438-1452.

Amihud, Y. and Lev, B. (1981). Risk reduction as a managerial motive for conglomerate mergers, The Bell Journal of Economics 12(2): 605-617.

Appelbaum, E. and Katz, E. (1986). Measures of risk aversion and comparative statics of industry equilibrium, The American Economic Review 76(3): 524-529.

Arrow, K. and Debreu, G. (1954). Existence of an equilibrium for a competitive economy, Econometrica: Journal of the Econometric Society pp. 265290 .

Asplund, M. (2002). Risk-averse firms in oligopoly, International Journal of Industrial Organization 20(7): 995-1012.

Awerbuch, S. (2000). Investing in photovoltaics: risk, accounting and the value of new technology, Energy Policy 28(14): 1023-1035.

Awerbuch, S. and Berger, M. (2003). Energy Security and Diversity in the EU: A Mean-Variance Portfolio Approach, IEA Research Paper.

Banal-Estanol, A. and Ottaviani, M. (2006). Mergers with Product Market Risk, Journal of Economics 83 Management Strategy 15(3): 577-608. 
Bar-Lev, D. and Katz, S. (1976). A portfolio approach to fossil fuel procurement in the electric utility industry, The Journal of Finance 31(3): 933947.

Baron, D. P. (1970). Price uncertainty, utility, and industry equilibrium in pure competition, International Economic Review 11(3): 463-480.

Baron, D. P. (1971). Demand uncertainty in imperfect competition, International Economic Review 12(2): 196-208.

Bessembinder, H. and Lemmon, M. (2002). Equilibrium pricing and optimal hedging in electricity forward markets, The Journal of Finance $57(3): 1347-1382$.

Blair, R. (1974). Random input prices and the theory of the firm, Economic Inquiry 12(2): 214-226.

Dhrymes, P. J. (1964). On the theory of the monopolistic multiproduct firm under uncertainty, International Economic Review 5(3): 239-257.

Diamond, P. A. (1967). The role of a stock market in a general equilibrium model with technological uncertainty, The American Economic Review 57(4): 759-776.

Ehrenmann, A. and Smeers, Y. (2011). Generation capacity expansion in a risky environment: a stochastic equilibrium analysis, Operations research 59(6): 1332-1346.

Fan, L., Hobbs, B. F. and Norman, C. S. (2010). Risk aversion and $\mathrm{co}_{2}$ regulatory uncertainty in power generation investment: Policy and mod- 
eling implications, Journal of Environmental Economics and Management 60(3): $193-208$.

Fan, L., Norman, C. and Patt, A. (2011). Electricity capacity investment under risk aversion: A case study of coal, gas, and concentrated solar power, Energy Economics 34(1): 54-61.

Hirshleifer, D. (1988). Risk, futures pricing, and the organization of production in commodity markets, The Journal of Political Economy 96(6): 12061220.

Holland, S. and Mansur, E. (2011). Is real-time pricing green? the environmental impacts of electricity demand variance, The Review of Economics and Statistics 90(3): 550-561.

Humphreys, H. and McClain, K. (1998). Reducing the impacts of energy price volatility through dynamic portfolio selection, The Energy Journal 19(3): 107-132.

Jansen, J., Beurskens, L. and van Tilburg, X. (2006). Application of portfolio analysis to the Dutch generating mix, Energy research Center at the Netherlands (ECN) report C-05-100 .

Lamont, A. D. (2008). Assessing the long-term system value of intermittent electric generation technologies, Energy Economics 30(3): 1208 - 1231.

URL: http://www.sciencedirect.com/science/article/pii/S0140988307000382

Leland, H. (1972). Theory of the firm facing uncertain demand, The American Economic Review 62(3): 278-291. 
Markowitz, H. (1952). Portfolio selection, The Journal of Finance 7(1): 7791.

May, D. O. (1995). Do managerial motives influence firm risk reduction strategies?, The Journal of Finance 50(4): 1291-1308.

McCall, J. (1967). Competitive production for constant risk utility functions, The Review of Economic Studies 34(4): 417-420.

McKinnon, R. I. (1967). Futures markets, buffer stocks, and income stability for primary producers, The Journal of Political Economy 75(6): 844-861.

Meunier, G. (2012). Risk aversion and technology portfolio, WP 10(1): 1-2.

Moschini, G. and Lapan, H. (1995). The hedging role of options and futures under joint price, basis, and production risk, International Economic Review 36(4): 1025-1049.

Nance, D. R., Smith, Clifford W., J. and Smithson, C. W. (1993). On the determinants of corporate hedging, The Journal of Finance 48(1): 267284 .

Neuhoff, K. and De Vries, L. (2004). Insufficient incentives for investment in electricity generations, Utilities Policy 12(4): 253-267.

Newbery, D. and Stiglitz, J. (1981). The theory of Commodity Price Stabilization.

Okuguchi, K. (1977). Input Price Uncertainty and the Theory of the Firm, Economic Studies Quarterly 28: 25-30. 
Roques, F. A., Newbery, D. M. and Nuttall, W. J. (2008). Fuel mix diversification incentives in liberalized electricity markets: A mean-variance portfolio theory approach, Energy Economics 30(4): 1831-1849.

Sandmo, A. (1971). On the theory of the competitive firm under price uncertainty, The American Economic Review 61(1): 65-73.

Stewart, M. (1978). Factor-price uncertainty with variable proportions, The American Economic Review 68(3): 468-473.

Tessitore, A. (1994). Market segmentation and oligopoly under uncertainty, Journal of Economics and Business 46(2): 65-75.

Wambach, A. (1999). Bertrand competition under cost uncertainty, International Journal of Industrial Organization 17(7): 941 - 951.

Willems, B. and Morbee, J. (2010). Market completeness: How options affect hedging and investments in the electricity sector, Energy Economics 32(4): 786-795.

Wolak, F. and Kolstad, C. (1991). A model of homogeneous input demand under price uncertainty, The American Economic Review 81(3): 514-538.

\section{Appendix A. Proof of Lemma}

Consider that an equilibrium exists.

- If technology $b$ is not used, then, $T_{b}=1$ and the derivative of the

objective of firm $i$, with respect to $k_{b}^{i}$, would be $\left(\bar{c}_{p}-c_{b}\right)-\left(I_{b}-I_{p}\right)+\frac{\lambda^{i}}{T} k^{i}$ which is strictly positive; therefore, firm $i$ would invest in technology $b$. 
- If technology $p$ is not used, then $k=k_{b}$ and $T=T_{b}$, the profits of the firms would not be random and the quantity $k_{b}$ would be such that $\left(v-c_{b}\right) T_{b}=I_{b}$, and the effect of a peak unit on the objective function would be $\left(v-\bar{c}_{p}\right) \frac{I_{b}}{v-c_{b}}-I_{p}$ which is strictly positive, because $r_{p}>r$. Hence, firm $i$ would invest in peak units.

Therefore, both technologies are used at equilibrium.

Then, with the expression of profit (2), the objective function (3) of a firm is

$$
U^{i}=\left[T\left(v-\bar{c}_{p}\right)-I_{p}\right] k^{i}+\left[T_{b}\left(\bar{c}_{p}-c_{b}\right)-\left(I_{b}-I_{p}\right)\right] k_{b}^{i}-\frac{\lambda^{i}}{2} \sigma^{2}\left(T k^{i}-T_{b} k_{b}^{i}\right)^{2}
$$

This function is maximized for positive and finite quantities if and only if $\left(v-\bar{c}_{p}\right)-I_{p} / T=-\left(\bar{c}_{p}-c_{b}\right)-\left(I_{b}-I_{p}\right) / T_{b}$. Therefore, this equality is satisfied and firms choose their capacities so that $k^{i}>k_{b}^{i} \geq 0$ and the following two first order conditions are satisfied:

$$
\begin{aligned}
\left(v-\bar{c}_{p}\right) T-I_{p} & =\lambda^{i} \sigma^{2} T\left(T k^{i}-T_{b} k_{b}^{i}\right) \\
\left(\bar{c}_{p}-c_{b}\right) T_{b}-\left(I_{b}-I_{p}\right) & =\lambda^{i} \sigma^{2} T_{b}\left(T_{b} k_{b}^{i}-T k^{i}\right) .
\end{aligned}
$$

Then, dividing all sides by $\lambda^{i}$ and summing over $i \in I$ one gets that the aggregate quantities of capacity are the solution of the two equations (7) and (8) with the expression of $\Lambda$ given by (9).

\section{Appendix B. Proof of Proposition 1}

\section{Existence of an equilibrium}

We show that there is $k$ and $k_{b}$ with $k>k_{b}>0$ such that (7) and (8) are satisfied. Then, if these quantities exist, there are individual quantities $k^{i}$ 
and $k_{b}^{i}$ that maximize firm $i$ objective for each $i \in I$ and such that $\sum_{i} k_{t}^{i}=k_{t}$, for instance $k^{i}=\Lambda / \lambda^{i} k$ and $k_{b}^{i}=\Lambda / \lambda^{i} k_{b}$ (but they are not unique).

From equations (7) and (8), we will use the fact that the risk-averse equilibrium is identical to a risk-neutral equilibrium with a peak variable cost $\bar{c}_{p}+\Lambda \sigma^{2}\left(T k-T_{b} k_{b}\right)$. Graphically, on Figure 2, we will rotate the line of the cost of the peak technology until the premium is equal to $\Lambda \sigma^{2}\left(T k-T_{b} k_{b}\right)$.

Let us denote by $k(\rho), k_{b}(\rho), T(\rho)$ and $T_{b}(\rho)$ the risk-neutral equilibrium quantities and durations for a variable cost $\bar{c}_{p}+\rho$. These are the solutions of

$$
T(\rho)=\frac{I_{p}}{v-\left(\bar{c}_{p}+\rho\right)}, T_{b}(\rho)=\frac{I_{b}-I_{p}}{\bar{c}_{p}+\rho-c_{b}}, k=F^{-1}(1-T) \text { and } k_{b}=F^{-1}\left(1-T_{b}\right)
$$

for $\rho$ between $\rho_{\min }=\left(I_{b}+c_{b}\right)-\left(I_{p}+\bar{c}_{p}\right)$ and $\rho_{\max }=\left(v-\bar{c}_{p}\right)+I_{p} / r_{b}$, at $\rho_{\min }$ (resp. $\rho_{\max }$ ) the peak (resp. base) technology is the sole technology used. Finally, let us define

$$
\Psi(\rho)=T(\rho) k(\rho)-T_{b}(\rho) k_{b}(\rho) .
$$

This function is continuous. For $\rho=\rho_{\min }$ it is strictly positive because $k_{b}\left(\rho_{\min }\right)=0$, and for $\rho=\rho_{\max }$ it is strictly negative because $k_{p}\left(\rho_{\max }\right)=0$. Consequently, there is at least one solution to $\rho=\Psi(\rho)$. For any such solution, the corresponding quantities $k(\rho)$ and $k_{b}(\rho)$ describe an equilibrium.

Type of equilibrium

At an equilibrium the difference $T k-T_{b} k_{b}$ is either positive or negative. Let us show that in the former case the equilibrium is of Type B, and that in the latter case it is of Type P.

- If at the equilibrium $T k-T_{b} k_{b}>0$ : 
- $\left(v-\bar{c}_{p}\right)-I_{p} / T>0$ by (7), so $T>T_{p}^{*}$ and the total quantity is lower than the risk-neutral total quantity.

- $\left(\bar{c}_{p}-c_{b}\right)-\left(I_{b}-I_{p}\right) / T_{b}<0$ by (8), so $T_{b}<T_{b}^{*}$ and the quantity of baseload capacity is lower than in the risk-neutral benchmark.

- The quantity of peak capacity is $k-k_{b}$, from the two previous comparisons it is lower than the risk-neutral quantity.

- If, at the equilibrium $T k-T_{b} k_{b}<0$ :

- $\left(v-\bar{c}_{p}\right)-I_{p} / T<0$ by $(7)$, so $T<T_{p}^{*}$ and the total quantity is larger than the risk-neutral total quantity.

- $\left(\bar{c}_{p}-c_{b}\right)-\left(I_{b}-I_{p}\right) / T_{b}>0$ by (8), so $T_{b}>T_{b}^{*}$ and the quantity of baseload capacity is larger than in the risk-neutral benchmark.

- The quantity of peak capacity is $k-k_{b}$, from the two previous comparisons it is larger than the risk-neutral quantity.

\section{Appendix C. Proof of proposition 2}

We use the function $\Psi$ defined by (B.1) to establish the result. The risk-neutral situation corresponds to $\rho=0$, and

$$
\Psi(0)=T^{*} k^{*}-T_{b}^{*} k_{b}^{*}=r_{p} F^{-1}\left(1-r_{p}\right)-r F^{-1}(1-r) .
$$

If $r_{p} F^{-1}\left(1-r_{p}\right)-r F^{-1}(1-r)>0$ then $\Psi(0)>0$ and, because $\Psi\left(\rho_{\max }\right)$ is negative, there is a solution to the equation $\rho=\Psi(\rho)$ in $\left(0, \rho_{\max }\right)$. Such a solution corresponds to an equilibrium of Type B because $T k-T_{b} k_{b}=$ $\Psi(\rho)=\rho>0$. A similar procedure could be performed for $r_{p} F^{-1}\left(1-r_{p}\right)-$ $r F^{-1}(1-r)<0$. 